\title{
Effects of cryopreservation on head morphometry and its relation with chromatin status in brown bear (Ursus arctos) spermatozoa
}

\author{
M. Álvarez a , V. García-Macías a, F. Martínez-Pastor c , F. Martínez a

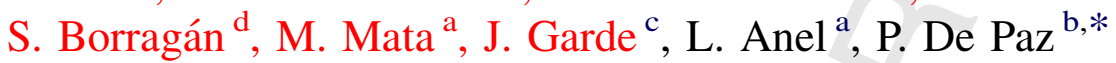 \\ a Animal Reproduction and Obstetrics, University of León, 24071 León, Spain \\ ${ }^{\mathrm{b}}$ Cell Biology, University of León, 24071 León, Spain \\ ${ }^{\mathrm{c}}$ National Wildlife Research Institute (IREC, CSIC-UCLM-JCCM), 02071 Albacete, Spain \\ ${ }^{\mathrm{d}}$ Cabarceno Park, Cantabria, Spain
}

Received 7 April 2008; received in revised form 19 June 2008; accepted 23 June 2008

\section{Abstract}

The Cantabrian brown bear (Ursus arctos) is a highly endangered species in Spain and basic studies are necessary in order to bank its germplasm. Sperm heads are mainly made up of chromatin, thus their shape depends partly on chromatin structure. Thawed semen from 10 bears was used to analyze chromatin status by sperm chromatin structure assay (SCSA) and head morphometry by the computer-assisted sperm morphology assessment (CASMA) system. Morphometry was analyzed before and after freezing thawing in order to evaluate the effects of cryopreservation on sperm heads. Each spermatozoon was measured for four primary parameters (length, $L$; width, $W$; area, $A$; perimeter, $P$ ) and derived parameters (ellipticity: $L / W$, circularity: $4 \pi A / P^{2}$, elongation: $(L-W) /(L+W)$, regularity: $\left.\pi L W / 4 A_{\AA}\right)$. All the derived parameters significantly differed between bears. Likewise, cryopreservation affected head morphometry by reducing its size. Clustering based on morphometric parameters separated three subpopulations, one of them being significantly more influenced by the cryopreservation process. We obtained high correlations between head morphometry and SCSA parameters: standard deviation of DNA fragmentation index (SD-DFI) was correlated with perimeter and area ( $r=0.75$ and $r=0.62$, respectively) and DFIm and DFIt (moderate and total DNA fragmentation index) were correlated with perimeter $(r=0.65$ and $r=0.67$, respectively). Nevertheless, classification of males according to SCSA or head morphometry did not completely agree so the two assays might explain male variability differently. We conclude that cryopreservation affected morphometry at least in a subset of spermatozoa. These results might improve future application of sperm banking techniques in this species.

(C) 2008 Published by Elsevier Inc.

Keywords: Bear; Sperm; Cryopreservation; Morphometry; Chromatin

\section{Introduction}

The Cantabrian brown bear (Ursus arctos) is a highly endangered species in Spain, and may constitutes the last pure breed population of brown bear in the world. This

\footnotetext{
* Corresponding author. Tel.: +34 987291204; fax: +34 987291322.

E-mail address: ppazc@unileon.es (P. De Paz).
}

population is currently split into two small nuclei (around 100 specimens), therefore inbreeding and loss of genetic variability are a recurrent hazard. A solution for this risk is to create Genetic Resource Banks,(GBRs) [1] which, in combination with assisted reproductive techniques, would support efforts to conserve this emblematic species. Our aim is to obtain baseline information on the quality of brown bear spermatozoa to eventually establish a germplasm repository for the species. 
The spermatozoon is a very specialized cell and its nucleus is a key structure in its reproductive role. Within the nucleus is the genetic material in the form of chromatin. Chromatin status was assessed using different techniques, but the sperm chromatin structure assay (SCSA) has many major advantages over others that are often labor intensive and lack statistical power [2]. SCSA is analyzed by flow cytometry, an objective and automatized process that allows a large number of cells to be counted in minimum time. This method has been applied in spermatozoa analysis in numerous species [see review in 3], and our group used it to analyze brown bear spermatozoa for the first time [4].

Sperm head morphometry has been evaluated in several species and various researchers have addressed the possible relationship between sperm head morphometry and fertility (human, 5; stallion, 6; boar, 7). Gravance et al. [8] stated that morphometry may be an indicator of sperm cryosurvivability. The introduction of computer-assisted sperm morphology assessment (CASMA) systems allowed more accurate and repeatable analyses of sperm morphometry to be performed and have revealed differences between individuals that cannot be detected using subjective methods [9]. The cryopreservation of spermatozoa has been found to affect chromatin structure and morphometry of the sperm head $[8,10,11]$. Thus it is reasonable to believe that the adverse effects of cryopreservation on sperm chromatin and head morphology may be responsible for lowered fertility of spermatozoa observed after cryopreservation. In conclusion, these parameters may be an important tool to study the quality of brown bear spermatozoa and to evaluate differences between individuals in sperm cryosurvivability. We hypothesize that sperm subpopulations could be detected in brown bear semen and that cryopreservation would alter the subpopulation pattern, as described for other species.

The current study was designed (1) to evaluate head morphometry and chromatin status of brown bear spermatozoa, ${ }^{(2)}$ to determine the effects of cryopreservation on bear sperm head morphometry, and (3) to determine whether sperm head morphology is related to sperm chromatin structure and thus we carried out tests to confirm if both sets of data agreed on classifying bears.

\section{Materials and methods}

All the products were obtained from Sigma (Madrid, Spain), unless otherwise specified.

\subsection{Animals and sample collection}

Animal manipulations were performed in accordance with Spanish Animal Protection Regulation RD223/1998, which conforms to European Union Regulation 86/609.

Semen samples from 10 bears were obtained by electroejaculation during the breeding season (May and June). Animal age was estimated that all the captured males were adults (at least 7 years old and not old). We control the bear population from 2000 and all the animals handled in the present work have been captured thereafter, the approximate age of bears were determined by craniological and morphometric indicators and one microchip is applied.

Animals were housed in a half-freedom regime in Cabarceno Park (Cantabria, Spain; $43^{\circ} 3 \not{\gamma} \mathrm{N}$ ), and fed with a diet based on chicken meat, bread and fruits; feeding followed the hierarchical order, the dominant bears taking most food. General anaesthesia was carried out by application of tiletamine + zolazepan (Zoletil100 ${ }^{\mathbb{R}}$; Virbac, Carros, France) $7 \mathrm{mg} / \mathrm{kg}$, and ketamine (Imalgene $1000{ }^{\circledR}$; Rhone-Mérieux, Lyon, France) 2 mg/ $\mathrm{kg}$. Electroejaculation was carried out with a PT Electronics ${ }^{\circledR}$ electroejaculator (PT Electronics, Boring, OR, USA). The transrectal probe was $320 \mathrm{~mm}$ long with a diameter of $26 \mathrm{~mm}$. Electric stimuli were given until ejaculation (10 V and $250 \mathrm{~mA}$, in average).

\subsection{Sample processing}

An aliquot of fresh sample was diluted in $2 \%$ glutaraldehyde (from 50\% solution in water, Panreac Quimica S.A., Barcelona, Spain) in BL1 medium (glucose $2.9 \mathrm{~g}$, sodium citrate anhydrous $1.0 \mathrm{~g}$, sodium bicarbonate $0.2 \mathrm{~g}$, and distilled water $100 \mathrm{~mL}$ ) at a sperm concentration of approximately $25 \times 10^{6}$ sperspermatozoa/mL, for morphometric analysis [9].

The remaining semen was diluted one-to-one in cryopreservation extender (Tes-Tris-Fructose complemented with $8 \%$ glycerol, $20 \%$ egg yolk, $2 \%$ EDTA and $1 \%$ equex; $320 \mathrm{mOsm} / \mathrm{kg}, \mathrm{pH} 7.1$ ) at $20^{\circ} \mathrm{C}$. The tubes of diluted sample (4\% glycerol) were put in glasses containing $100 \mathrm{~mL}$ of water at room temperature and transferred to refrigerator, so temperature decreased smoothly until a thermometer show $5{ }^{\circ} \mathrm{C}$ at water (70$80 \mathrm{~min}$ ). Next, a second dilution 1:1 was performed at $5{ }^{\circ} \mathrm{C}$ with the same diluents containing $12 \%$ glycerol so finally the rediluted sample contains $8 \%$ glycerol. At this moment we adjust the sample to obtain a final concentration of $100 \times 10^{6} \mathrm{spz} / \mathrm{mL}$ adding TTF diluents ( $8 \%$ glycerol). After packaging into $0.25 \mathrm{~mL}$ plastic 
straws and equilibration for $1 \mathrm{~h}$ at $5{ }^{\circ} \mathrm{C}$, the sample was frozen in a programmable biofreezer (Kryo 10-16 II Planer ${ }^{\mathrm{TM}}$ ) at $-20{ }^{\circ} \mathrm{C} / \mathrm{min}$ down to $-100{ }^{\circ} \mathrm{C}$, and then transferred to liquid nitrogen containers. The cryopreserved samples remained in liquid nitrogen for a minimum of 1 week. Thawing was performed by dropping the straws in water at $65{ }^{\circ} \mathrm{C}$ for 6 s immediately prior to processing for analysis at room temperature. One aliquot was taken from the thawed sample and fixed in $2 \%$ glutaraldehyde for morphometric analysis (as previously described) and another aliquot was analyzed for chromatin status, using the SCSA.

A semen analysis is performed previously. We have used just urine-free samples (proved using Merckognost Urea Rapid Screening test, Merck, Barcelona, Spain).

The fresh semen samples of brown bear showed the following mean values: $\mathrm{pH}, 8.8$; osmolarity, $292.4 \mathrm{mOs}$; concentration, $470.6 \times 10^{6} \mathrm{spz} / \mathrm{mL}$ and progressive motility $70.9 \%$. The frozen-thawed sample showed $33.9 \%$ progressive motility.

\subsection{Morphometric analysis (CASMA)}

Aliquots fixed in $2 \%$ glutaraldehyde (fresh and thawed sperm) were smeared on microscope slides by placing $5 \mu \mathrm{L}$ of sample on the clear end of a frosted slide and dragging a second microscope slide across the drop. The slides were air dried for a minimum of $2 \mathrm{~h}$ and stained using Diff-Quik (QCA, Tarragona, Spain). Slides were immersed for $10 \mathrm{~min}$ in the solution A and 15 min in the solution B. Subsequently, the slides were rinsed in distilled water, air dried and mounted. They were examined using a Nikon Labophot-2 microscope (Nikon, Tokyo, Japan) equipped with a $60 \times$ bright field objective. The video signal was acquired using a Sony XC-75CE video camera (Sony Corporation, Tokyo, Japan) interfaced with a computer with the CASMA software Sperm-Class Analyser ${ }^{\circledR}$ (SCA2002; Microptic S.L., Barcelona, Spain). The camera provided digitized images of $752 \times 582$ pixels and the image resolution was $8.6 \mu \mathrm{m}$ per pixel in the horizontal and $8.3 \mu \mathrm{m}$ per pixel in the vertical axes.

A mean of 150 cells on two slides were acquired and analyzed with the CASMA software. The accuracy of the automatic analysis was confirmed using the options provided by the software, and those heads wrongly analyzed were removed from the analysis. Thus, we obtained data from over 100 cells/slide ${ }_{\Lambda}^{[11]}$.

For each sperm head, the CASMA system yielded four primary parameters: head area $\left(A, \mu \mathrm{m}^{2}\right)$, head perimeter $(P, \mu \mathrm{m})$, head length $(L, \mu \mathrm{m})$, and head width $(W, \mu \mathrm{m})$; and four derived parameters of head shape: ellipticity $(L / W)$, circularity (form factor; $\left.4 \pi A / P^{2}\right)$,

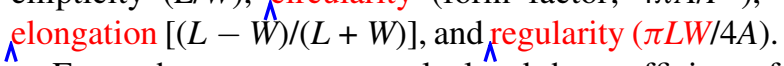

For each parameter, we calculated the coefficient of variation $(\mathrm{CV})$, both within-animal (estimated as the mean of each individual CV) and between animals (estimated as the $\mathrm{CV}$ of within-animal CV), in order to find out the best parameters to discriminate among animals on the basis of these sperm morphology parameters [12].

\subsection{Sperm chromatin structure assay (SCSA)}

An aliquot of thawed sperm sample from each male was diluted with TNE buffer (0.01 M Tris- $\mathrm{HCl}, 0.15 \mathrm{M}$ $\mathrm{NaCl}, 1$ mM EDTA; $\mathrm{pH} 7.4,4{ }^{\circ} \mathrm{C}$ ) in polypropylene tubes at a final sperm concentration of approximately 1$2 \times 10^{6}$ cells $/ \mathrm{mL}$. For analysis, $200 \mu \mathrm{L}$ of sample in TNE were mixed with $400 \mu \mathrm{L}$ of acid-detergent solution $(0.08 \mathrm{~N} \mathrm{HCl}, 0.15 \mathrm{M} \mathrm{NaCl}, 0.1 \%$ Triton X100; $\mathrm{pH} 1.2$, $4{ }^{\circ} \mathrm{C}$ ) in flow cytometry polypropylene tubes. Exactly $30 \mathrm{~s}$ later, $1.2 \mathrm{~mL}$ of acridine orange (AO) staining solution $\left(0.037 \mathrm{M}\right.$ citric acid, $0.126 \mathrm{M} \mathrm{Na} \mathrm{NPO}_{4}$, $0.0011 \mathrm{M}$ dissodium EDTA, $0.15 \mathrm{M} \mathrm{NaCl} ; \mathrm{pH} 6.0$, $4{ }^{\circ} \mathrm{C}$ ), containing $6 \mu \mathrm{g} / \mathrm{mL}$ electrophoretically purified AO (Polysciences, Warrington, PA, USA) was added. The stained samples were analyzed just 3 min after AO staining.

The samples were analyzed on a FACScalibur flow cytometer (Becton Dickinson; San Jose, CA, USA), equipped with standard optics and an argon-laser tuned at $488 \mu \mathrm{m}$ and running at $200 \mathrm{~mW}$. Calibration was carried out periodically using standard beads (Calibrites; Becton Dickinson). We obtained 10,000 events per sample with a flow rate of 200-250 cells/s. Data corresponding to the red (FL3) and green fluorescence (FL1) of acquired particles were recorded (Cell Quest v.3 software; Becton Dickinson). We used an ejaculated sample as standard to routinely adjust cytometer settings in order to make measurements from different sessions comparable.

We calculated the DNA Fragmentation Index (DFI) of each event (spermatozoa) as the relation between red and total fluorescence, by means of the formula red/ $($ red + green $) \times 100$. Then, we classified the spermatozoa into three groups, according to DFI: normal DFI $(<20 \% \mathrm{DFI})$, moderate DFI (from $20 \%$ to $75 \% \mathrm{DFI}$ ) and high DFI (from $75 \%$ to $100 \%$ DFI); we calculated the percentage of spermatozoa with a moderate (DFIm) and high (DFIh) DNA fragmentation index for each sample. Total DNA fragmentation index (DFIt) was defined as DFIm + DFIh. We also calculated the mean of DFI and standard deviation of DFI (SD DFI) for each sample. Also, we detected spermatozoa with high DNA stainability (HDS; FL1 channels above main population 
in FL1/FL3 flow cytometry dot plot). High DNAstainable (HDS) spermatozoa is another distinct population in semen that characterizes immature spermatozoa. Recent data support the idea that high DNA stainability can significantly influence male fertility potential and that this biomarker is currently utilized in infertility investigations $\wedge^{[2]}$.

\subsection{Statistical analysis}

Statistical analyses were performed with the SAS ${ }^{\mathrm{TM}}$ v.8 package (SAS Institute Inc., Cary, NC, USA) unless otherwise specified.

General linear models (GLMs) procedure was used to perform analysis of variance with individual bears as factor. Spearman correlation coefficients were used to calculate the relationships between head morphometry parameters and SCSA parameters. The effect of cryopreservation on sperm head morphometry within and between bears was analyzed by Student's $t$-test, to compare morphometric parameters, before and after freezing/thawing.
In order to classify the bears based on SCSA or head morphometric parameters we used the PRINCOMP procedure (principal component analysis: PCA) to derive a small number of linear combinations (principal components or factor, PC) retaining the most information in the original variables (morphometric or SCSA parameters). This procedure aimed to classify the cases in the space generated by the PC axes too. The Kaiser criterion was used to decide the number of factors to be retained (principal components). The plots of factor coordinates and graphs for males were obtained with the Principal Components and Classification Analysis module of the program STATISTICA 7 (StatSoft, Tulsa, USA).

In order to find the subpopulation structure, if any, in the morphometry data, we performed a non-hierarchical cluster analysis, using principal components in place of the original variables, by means of the FASTCLUS procedure ( $k$-means procedure). The CLUSTER procedure was applied afterwards to perform a hierarchical clustering. We obtained three clusters, named CL1, CL2 and CL3. Then, we compared the clusters obtained from

Table 1

Morphometric parameters of the sperm head and derived parameters in each bear in fresh $(\mathrm{F})$ and thawed $(\mathrm{T})$ semen expressed as mean $(\mathrm{CV}$ in percentage)

\begin{tabular}{|c|c|c|c|c|c|c|c|c|c|}
\hline & & Length & Width & Area & Perimeter & Ellipticity & Circularity & Elongation & Regularity \\
\hline \multirow[t]{2}{*}{ Bear 1} & $\mathrm{~F}$ & $5.82(5.7)^{\mathrm{a}}$ & $4.25(4.6)^{\mathrm{a}}$ & $21.00(8.0)^{\mathrm{a}}$ & $17.58(4.2)^{\mathrm{a}}$ & $1.37(5.7)^{\mathrm{a}}$ & $0.85(2.7)^{\mathrm{a}}$ & $0.16(17.5)^{\mathrm{a}}$ & $0.93(3.5)^{\mathrm{a}}$ \\
\hline & $\mathrm{T}$ & $5.81(13.7)^{\mathrm{a}}$ & $4.29(5.3)^{\mathrm{a}}$ & $20.79(9.4)^{\mathrm{a}}$ & $17.55(9.6)^{\mathrm{a}}$ & $1.36(19.1)^{\mathrm{a}}$ & $0.85(6.4)^{\mathrm{a}}$ & $0.15(34.0)^{\mathrm{a}}$ & $0.94(4.5)^{\mathrm{b}}$ \\
\hline \multirow[t]{2}{*}{ Bear 2} & F & $6.21(8.5)^{\mathrm{a}}$ & $4.42(5.5)^{\mathrm{a}}$ & $22.76(9.4)^{\mathrm{a}}$ & $18.43(6.0)^{\mathrm{a}}$ & $1.41(7.9)^{\mathrm{a}}$ & $0.84(4.7)^{\mathrm{a}}$ & $0.17(22.1)^{\mathrm{a}}$ & $0.95(5.2)^{\mathrm{a}}$ \\
\hline & $\mathrm{T}$ & $5.44(4.1)^{\mathrm{b}}$ & $4.24(4.0)^{\mathrm{b}}$ & $19.62(6.5)^{\mathrm{b}}$ & $16.85(3.5)^{b}$ & $1.29(4.5)^{\mathrm{b}}$ & $0.87(2.2)^{\mathrm{b}}$ & $0.12(17.6)^{b}$ & $0.92(3.4)^{\mathrm{b}}$ \\
\hline \multirow[t]{2}{*}{ Bear 3} & $\mathrm{~F}$ & $6.00(8.5)^{\mathrm{a}}$ & $4.39(5.4)^{\mathrm{a}}$ & $21.42(8.3)^{\mathrm{a}}$ & $17.89(6.0)^{\mathrm{a}}$ & $1.37(8.3)^{\mathrm{a}}$ & $0.84(5.4)^{\mathrm{a}}$ & $0.15(26.0)^{\mathrm{a}}$ & $0.97(5.4)^{\mathrm{a}}$ \\
\hline & $\mathrm{T}$ & $5.83(8.4)^{\mathrm{b}}$ & $4.43(5.6)^{\mathrm{a}}$ & $20.70(10.3)^{b}$ & $17.51(7.1)^{\mathrm{b}}$ & $1.32(8.4)^{b}$ & $0.85(5.8)^{\mathrm{a}}$ & $0.13(30.7)^{\mathrm{b}}$ & $0.98(4.5)^{b}$ \\
\hline \multirow[t]{2}{*}{ Bear 4} & $F$ & $5.74(5.1)^{\mathrm{a}}$ & $4.40(4.5)^{\mathrm{a}}$ & $21.25(6.6)^{\mathrm{a}}$ & $17.68(3.7)^{\mathrm{a}}$ & $1.31(5.6)^{\mathrm{a}}$ & $0.85(2.7)^{\mathrm{a}}$ & $0.13(20.4)^{\mathrm{a}}$ & $0.94(3.5)^{\mathrm{a}}$ \\
\hline & $\mathrm{T}$ & $6.14(6.6)^{\mathrm{b}}$ & $4.55(4.7)^{\mathrm{b}}$ & $21.80(8.1)^{\mathrm{b}}$ & $18.26(5.4)^{\mathrm{b}}$ & $1.35(7.8)^{\mathrm{b}}$ & $0.82(4.8)^{\mathrm{b}}$ & $0.14(26.0)^{\mathrm{b}}$ & $1.00(4.1)^{\mathrm{b}}$ \\
\hline \multirow[t]{2}{*}{ Bear 5} & $\mathrm{~F}$ & $6.33(9.1)^{\mathrm{a}}$ & $4.47(4.9)^{\mathrm{a}}$ & $23.15(9.0)^{\mathrm{a}}$ & $18.73(6.1)^{\mathrm{a}}$ & $1.42(8.6)^{\mathrm{a}}$ & $0.83(5.4)^{\mathrm{a}}$ & $0.17(24.0)^{\mathrm{a}}$ & $0.96(5.6)^{\mathrm{a}}$ \\
\hline & $\mathrm{T}$ & $6.28(6.4)^{\mathrm{a}}$ & $4.67(5.4)^{\mathrm{b}}$ & $22.97(8.9)^{\mathrm{a}}$ & $18.72(6.1)^{\mathrm{a}}$ & $1.35(7.3)^{\mathrm{b}}$ & $0.82(4.9)^{\mathrm{a}}$ & $0.15(24.4)^{\mathrm{b}}$ & $1.00(3.7)^{\mathrm{b}}$ \\
\hline \multirow[t]{2}{*}{ Bear 6} & $\mathrm{~F}$ & $6.16(3.6)^{\mathrm{a}}$ & $4.54(4.7)^{\mathrm{a}}$ & $23.22(5.9)^{\mathrm{a}}$ & $18.20(3.0)^{\mathrm{a}}$ & $1.36(5.5)^{\mathrm{a}}$ & $0.88(2.2)^{\mathrm{a}}$ & $0.15(17.6)^{\mathrm{a}}$ & $0.95(2.9)^{\mathrm{a}}$ \\
\hline & $\mathrm{T}$ & $5.98(4.7)^{\mathrm{b}}$ & $4.47(4.1)^{\mathrm{b}}$ & $22.1(7.1)^{\mathrm{b}}$ & $17.73(4.3)^{\mathrm{b}}$ & $1.34(4.9)^{\mathrm{b}}$ & $0.88(2.8)^{\mathrm{a}}$ & $0.14(17.9)^{\mathrm{b}}$ & $0.95(3.0)^{\mathrm{a}}$ \\
\hline \multirow[t]{2}{*}{ Bear 7} & F & $6.09(4.2)^{\mathrm{a}}$ & $4.60(4.1)^{\mathrm{a}}$ & $23.13(6)^{\mathrm{a}}$ & $18.18(3.3)^{\mathrm{a}}$ & $1.33(5.1)^{\mathrm{a}}$ & $0.88(2.1)^{\mathrm{a}}$ & $0.14(18.2)^{\mathrm{a}}$ & $0.95(2.8)^{\mathrm{a}}$ \\
\hline & $\mathrm{T}$ & $5.70(7.2)^{\mathrm{b}}$ & $4.34(4.4)^{\mathrm{b}}$ & $20.34(6.8)^{b}$ & $17.02(4.8)^{\mathrm{b}}$ & $1.31(7.5)^{\mathrm{a}}$ & $0.88(4.5)^{\mathrm{a}}$ & $0.14(28)^{\mathrm{a}}$ & $0.96(4.5)^{\mathrm{a}}$ \\
\hline \multirow[t]{2}{*}{ Bear 8} & $\mathrm{~F}$ & $6.09(8.0)^{\mathrm{a}}$ & $4.39(4.9)^{\mathrm{a}}$ & $21.67(7.6)^{\mathrm{a}}$ & $18.04(5.4)^{\mathrm{a}}$ & $1.39(9.3)^{\mathrm{a}}$ & $0.84(5.1)^{\mathrm{a}}$ & $0.16(27.8)^{\mathrm{a}}$ & $0.97(4.6)^{\mathrm{a}}$ \\
\hline & $\mathrm{T}$ & $5.80(7.2)^{\mathrm{b}}$ & $4.43(4.4)^{\mathrm{b}}$ & $20.36(6.8)^{b}$ & $20.36(4.8)^{\mathrm{b}}$ & $1.31(7.5)^{\mathrm{b}}$ & $0.85(4.5)^{\mathrm{b}}$ & $0.13(28.0)^{\mathrm{b}}$ & $0.99(4.5)^{\mathrm{b}}$ \\
\hline \multirow[t]{2}{*}{ Bear 9} & $\mathrm{~F}$ & $6.06(6.4)^{\mathrm{a}}$ & $4.46(4.5)^{\mathrm{a}}$ & $22.63(8.6)^{\mathrm{a}}$ & $18.55(4.5)^{\mathrm{a}}$ & $1.36(5.7)^{\mathrm{a}}$ & $0.83(3.3)^{\mathrm{a}}$ & $0.15(19.5)^{\mathrm{a}}$ & $0.94(4.0)^{\mathrm{a}}$ \\
\hline & $\mathrm{T}$ & $5.80(9.9)^{\mathrm{a}}$ & $4.39(5.6)^{\mathrm{a}}$ & $20.33(12.2)^{\mathrm{b}}$ & $17.34(7.8)^{\mathrm{b}}$ & $1.32(9.3)^{\mathrm{a}}$ & $0.85(5.2)^{\mathrm{a}}$ & $0.14(32.1)^{\mathrm{a}}$ & $0.98(4.0)^{\mathrm{b}}$ \\
\hline \multirow[t]{2}{*}{ Bear 10} & $\mathrm{~F}$ & $6.27(7.7)^{\mathrm{a}}$ & $4.39(4.5)^{\mathrm{a}}$ & $22.08(8.7)^{\mathrm{a}}$ & $18.44(6.0)^{\mathrm{a}}$ & $1.43(8.1)^{\mathrm{a}}$ & $0.82(5.7)^{\mathrm{a}}$ & $0.18(22.1)^{\mathrm{a}}$ & $0.98(4.4)^{\mathrm{a}}$ \\
\hline & $\mathrm{T}$ & $6.03(9.1)^{\mathrm{b}}$ & $4.38(4.2)^{\mathrm{a}}$ & $20.70(9.5)^{\mathrm{b}}$ & $17.54(6.8)^{b}$ & $1.38(8.8)^{\mathrm{b}}$ & $0.85(5.6)^{\mathrm{b}}$ & $0.15(26.8)^{\mathrm{b}}$ & $1.00(4.6)^{\mathrm{a}}$ \\
\hline \multirow[t]{2}{*}{ Average } & $\mathrm{F}$ & $6.09(7.6)^{\mathrm{a}}$ & $4.42(5.2)^{\mathrm{a}}$ & $22.20(8.7)^{\mathrm{a}}$ & $18.15(5.3)^{\mathrm{a}}$ & $1.38(7.8)^{\mathrm{a}}$ & $0.85(4.7)^{\mathrm{a}}$ & $0.16(23.8)^{\mathrm{a}}$ & $0.95(4.6)^{\mathrm{a}}$ \\
\hline & $\mathrm{T}$ & $5.87(8.8)^{\mathrm{b}}$ & $4.41(5.5)^{\mathrm{a}}$ & $20.93(9.8)^{\mathrm{b}}$ & $17.55(6.8)^{b}$ & $1.33(9.4)^{\mathrm{b}}$ & $0.85(5.1)^{\mathrm{a}}$ & $0.14(26.9)^{\mathrm{a}}$ & $0.97(4.8)^{\mathrm{b}}$ \\
\hline
\end{tabular}

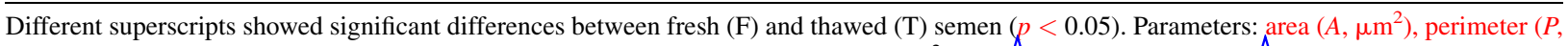
$\mu \mathrm{m})$, length $(L, \mu \mathrm{m})$, width $(W, \mu \mathrm{m})$, ellipticity $(L / W)$, circularity (form factor; $\left.4 \pi A / P^{2}\right)$, elongation $[(L-W) /(L+W)]$, and regularity $(\pi L W / 4 A)$. 
Table 2

Within ejaculate CV (expressed as the mean of individual values) and between-animal $\mathrm{CV}$ in fresh sperm

\begin{tabular}{lcc}
\hline & $\begin{array}{c}\text { CVs within } \\
\text { animals (\%) }\end{array}$ & $\begin{array}{c}\text { CVs between } \\
\text { animals (\%) }\end{array}$ \\
\hline Length & 6.68 & 29.2 \\
Width & 4.76 & 9.03 \\
Area & 7.81 & 16.00 \\
Perimeter & 4.82 & 25.42 \\
Ellipticity & 6.98 & 22.78 \\
Circularity & 3.93 & 37.15 \\
Elongation & 21.5 & 16.56 \\
Regularity & 4.19 & 24.22 \\
\hline
\end{tabular}

the datasets before and after freezing/thawing (GLM procedure).

\section{Results}

\subsection{Head morphometry of fresh spermatozoa}

Average results of sperm head dimensions for fresh semen were $6.09 \mu \mathrm{m}$ for length, $4.42 \mu \mathrm{m}$ for width, $22.20 \mu \mathrm{m}^{2}$ for area and $18.15 \mu \mathrm{m}$ for perimeter. Table 1 displays individual results for each male, showing large variations in all the morphometric parameters between bears. Thus, within-male CVs (pooled data) of different parameters ranged from 3.93 (circularity) to 21.5 (elongation) and between-male CVs ranged from 9.03 (width) to 37.15 (circularity) (Table 2).

\subsection{Head morphometry of frozen-thawed spermatozoa}

On average, bear sperm heads were smaller $(p<0.01)$ in cryopreserved samples than in the companion fresh samples for length $(5.87 \mu \mathrm{m})$, area $\left(20.93 \mu \mathrm{m}^{2}\right)$ and perimeter $(17.55 \mu \mathrm{m})$, and there was a reduction in the derived parameters ellipticity and regularity (Table 1). Likewise, cryopreserved samples had higher within-male CVs for all the studied parameters. When the bears were studied individually, we confirmed a significant reduction in area, length and perimeter in 7 bears $(2,3,4,6,7,8$ and 10) after cryopreservation.

The cluster analysis using morphometry parameters allowed fresh and frozen/thawed spermatozoa to be classified in three clusters: CL1, CL2 and CL3 (Table 3). CL1, containing elongated spermatozoa, underwent a slight decrease in the percentage of spermatozoa after thawing while CL2 (more rounded heads) showed an increase in this percentage after thawing. Furthermore, the head area of spermatozoa in cluster 2 decreased slightly after cryopreservation. CL3, characterized by having a smaller head area, did not apparently vary with cryopreservation.

\subsection{SCSA parameters of bear sperm and its relation with head morphometry}

Individual SCSA results are shown in Table 4. Bear 9 presented the highest DNA fragmentation index values (DFIh: 7.67\%, and DFIt: $17.50 \%$ ), while bear 8 yielded the lowest (DFIh: $0.83 \%$ and DFIt: $3.10 \%$ ).

There were significant correlations between SCSA and CASMA parameters (Table 5). The SD-DFI showed a positive correlation with perimeter $(r=0.75 ; p>0.01)$ and area $(r=0.62 ; p>0.05)$. DFIh and DFIt correlated with perimeter $(r=0.65$ and $r=0.67$, respectively; $p<$ $\Lambda^{0.05) \text {. }}$

Table 3

Mean values of morphometry parameters and percentage in each of the subpopulations of bear spermatozoa yielded by the cluster analysis (CL1, CL2 and CL3) in fresh and frozen/thawed spermatozoa ${ }^{a}$

\begin{tabular}{|c|c|c|c|c|c|c|}
\hline & \multicolumn{2}{|l|}{ CL1 } & \multicolumn{2}{|l|}{ CL2 } & \multicolumn{2}{|l|}{ CL3 } \\
\hline & Fresh & Thawed & Fresh & Thawed & Fresh & Thawed \\
\hline Length & 6.37 & 6.46 & 6.00 & 5.87 & 5.70 & 5.89 \\
\hline Width & 4.43 & 4.60 & 4.70 & 4.60 & 4.27 & 4.19 \\
\hline Area & 22.86 & 23.12 & 23.49 & 21.82 & 20.53 & 20.05 \\
\hline Perimeter & 18.61 & 18.86 & 18.40 & 17.85 & 17.29 & 17.18 \\
\hline Ellipticity & 1.44 & 1.41 & 1.28 & 1.28 & 1.33 & 1.41 \\
\hline Circularity & 0.83 & 0.82 & 0.87 & 0.86 & 0.86 & 0.85 \\
\hline Elongation & 0.18 & 0.17 & 0.12 & 0.12 & 0.14 & 0.17 \\
\hline Regularity & 0.97 & 1.01 & 0.94 & 0.97 & 0.93 & 0.97 \\
\hline Spermatozoa (\%) & 34.72 & 32.57 & 35.59 & 38.16 & 29.69 & 29.27 \\
\hline
\end{tabular}

${ }_{1}^{a}$ Cluster 1 (CL1), Cluster 2 (CL2) and Cluster 3 (CL3) are defined in spermatozoa population of each bear by means of non-hierarchical cluster analysis, using principal components in place of the original variables. These individual clusters, obtained before and after freezing/thawing, were analyzed obtaining the mean values. 
Table 4

SCSA parameters of thawed sperm sample for each male ${ }^{a}$

\begin{tabular}{llrlllr}
\hline & Mean DFI & SD DFI & HDS & DFIh & DFIm & DFIt \\
\hline Bear 1 & 175.8 & 6.90 & 0.90 & 1.42 & 2.84 & 4.26 \\
Bear 2 & 201.3 & 11.51 & 0.18 & 4.41 & 6.35 & 10.76 \\
Bear 3 & 183.7 & 7.46 & 1.90 & 1.68 & 3.58 & 5.26 \\
Bear 4 & 180.7 & 5.48 & 0.56 & 0.84 & 3.18 & 4.02 \\
Bear 5 & 192.1 & 12.14 & 1.12 & 3.69 & 5.30 & 8.99 \\
Bear 6 & 200.1 & 7.41 & 0.14 & 1.29 & 2.79 & 4.08 \\
Bear 7 & 232.1 & 13.26 & 0.37 & 4.34 & 8.45 & 12.79 \\
Bear 8 & 196.4 & 5.56 & 0.23 & 0.83 & 2.27 & 3.10 \\
Bear 9 & 256.2 & 17.61 & 0.37 & 7.67 & 9.83 & 17.50 \\
Bear 10 & 214.3 & 10.48 & 1.97 & 2.74 & 6.08 & 8.82 \\
\hline
\end{tabular}

${ }_{1}^{a}$ DFI: DNA fragmentation index; mean DFI (0-1000 channels) SD DFI: standard deviation; HDS: high DNA stainability; DFIh: high DFI; DFIm: moderate DFI and DFIt: total DFI. The spermatozoa were classified into three groups, according to DFI: normal DFI $(<20 \%$ DFI), moderate DFI (from $20 \%$ to $75 \%$ DFI) and high DFI (from $75 \%$ to $100 \% \mathrm{DFI})$. We calculated the total DNA fragmentation index (DFIt) as DFIm + DFIh. The mean of DFI and standard deviation of DFI (SD DFI) for each sample were calculated. Also, we detected spermatozoa with high DNA stainability (HDS)

The principal component analysis (PCA) applied to SCSA parameters rendered two principal components (Table 6a): Factor 1, including SD DFI, DFIm, DFIh and DFIt (high negative coefficients), and Factor 2, representing mainly HDS (positive coefficient). In the case of morphometric parameters (Table 6b), we obtained two principal components: Factor 1, including most parameters (negative coefficients), and Factor 2, consisting mainly of Area, Width and circularity (positive coefficient). The circularity parameter was present in both factors.

The classifications of males according to Factor 1 and Factor 2 based on SCSA parameters (Fig. 1a) showed that bears 1, 4, 6 and 8 would be the animals having normal chromatin status (DFI $<20 \%$ ), whereas bears 2,7 and 9 would have higher chromatin instability

Table 5

Spearman correlation coefficients between SCSA and CASMA (head morphometry) parameters (see Table 4 to description of SCSA parameters)

\begin{tabular}{lcrrrrc}
\hline & Mean DFI & SD-DFI & HDS & DFIm & DFIh & DFIt \\
\hline Length & 0.51 & 0.55 & -0.01 & 0.39 & 0.45 & 0.49 \\
Width & 0.52 & 0.60 & -0.37 & 0.42 & 0.47 & 0.52 \\
Area & 0.56 & $0.62^{*}$ & -0.34 & 0.45 & 0.47 & 0.52 \\
Perimeter & 0.67 & $0.75^{* *}$ & -0.04 & 0.59 & $0.65^{* *}$ & $0.67^{* *}$ \\
Ellipticity & 0.02 & 0.01 & 0.29 & 0.06 & -0.02 & -0.04 \\
Circularity & -0.22 & -0.21 & -0.40 & -0.31 & -0.20 & -0.2 \\
Elongation & 0.09 & 0.08 & 0.19 & 0.04 & 0.09 & 0.04 \\
Regularity & 0.80 & 0.04 & 0.34 & 0.33 & -0.10 & 0.04
\end{tabular}

Table 6

Factor coordinates of the variables (see Table 4 to description of SCSA parameters) $)^{a}$

\begin{tabular}{lrr}
\hline Variable & Factor 1 & Factor 2 \\
\hline (a) SCSA & & \\
SdDFI & -0.9777 & 0.0919 \\
HDSn & 0.1799 & 0.9833 \\
DFIh & -0.9728 & 0.0099 \\
DFImn & -0.9839 & 0.0982 \\
DFItn & -0.9305 & -0.0207 \\
(b) Morphometry & & \\
Length & -0.9567 & 0.2676 \\
Width & -0.2014 & 0.9540 \\
Area & -0.5546 & 0.8094 \\
Perimeter & -0.8667 & 0.3544 \\
Ellipticity & -0.8880 & -0.4036 \\
Circularity & 0.5103 & 0.6983 \\
Elongation & -0.8337 & -0.4364 \\
Regularity & -0.6470 & -0.1943 \\
\hline
\end{tabular}

${ }^{\text {a }}$ Interpretation of the principal components must be done in terms of the correlation. With this fact in mind, given a set of variables you should be looking for those variables that have the highest (absolute) values of the factor coordinates for the given factors. Because the current analysis is based on correlations, the largest factor coordinate (absolute values) that can occur is equal to 1.0.

(the DFI indexes being higher in comparison with the first group of bears), and bears 3,5 and 10, with intermediate DFI values, would have more immature chromatin (higher HDS in comparison with the rest of the bears). The classification of males according to morphometric parameters is shown in Fig. 1b. In this case, the grouping of males is different to the SCSA classification. Males 6, 7 and 9 were grouped together as their spermatozoa had greater circularity and head size, whereas in males 1,3 and 4 the size was lower and spermatozoa in bears 2, 5 and 10 had greater ellipticity.

\section{Discussion}

In this study we have carried out for the first time a description of the morphometric traits of the sperm head of brown bear and the effects of cryopreservation on these parameters. One of the most striking findings in our study was the high within-male heterogeneity on the morphometric data, as in human spermatozoa [5] or in $\operatorname{dog}$ [13]. In contrast, spermatozoa of other species show a relatively constant intra-animal morphology (ram [9], cynomolgus monkey [14] and mouse [15]). Moreover, variability among males was very high too (CVs: $9.03 \%$ for width and $37.15 \%$ for circularity). Sancho et al. [9] also observed high variability between rams (CVs 11.98 $-40.83 \%)$, but in other species sperm morphometry is 
(a)
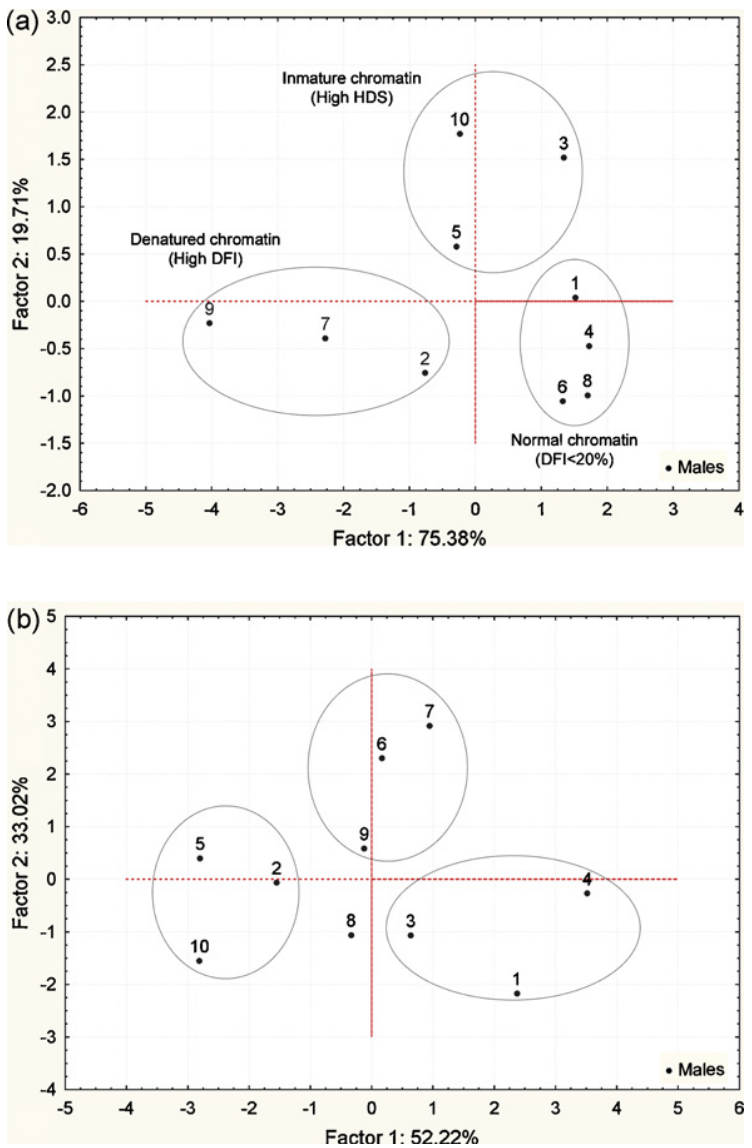

Fig. 1. Location of the males depending on chromatin status detected by SCSA (a) and depending on head sperm morphometry (b). The males are represented by different numbers in the multidimensional space defined by the first two principal components extracted from PCA (Factor1 and Factor2). In SCSA the first two factors accounts for approximately $95.09 \%$ of the total variance $(75.38+19.71)$. In morphometry, these two factors accounts for approximately $86.24 \%$ of the total variance $(52.22+33.02)$. See Table 6 for factor coordinates. ranged from $1.3 \%$ to $13 \%$ in alpaca [12] and bull sperm values were in the interval of $3.1-5.6 \%$ [8]. These variations in sperm morphology between males could affect sperm freezability and are indicative of genetic variations responsible for the relative ability to withstand freezing procedures [16].

One of the most important steps in the characterization of head sperm morphometry is to establish the most representative parameters for each species [12]. In the present work, circularity had a relatively low withinanimal CV (3.93\%), but a relatively high betweenanimal CV (37.15\%). Therefore, this may be the most suitable morphometric parameter for discriminating among brown bears. Other parameters, such as regularity and perimeter could be good indicators of differences between bears too. Studies in other species have also shown that circularity (shape factor) and perimeter might be suitable parameters for male discrimination (cynomolgus monkey [14] and alpaca [12]). Nevertheless, other parameters might also be useful, such as the sperm head width/length ratio (rabbit [17]).

We also found that some morphometric parameters changed after cryopreservation. The cryopreservation process is associated with sperm function damage, loss of membrane selective permeability and changes in membrane fluidity, reduction in motility, enzyme activity and viability [18]. In this study, we observed lower values for length, width, area and perimeter after the cryopreservation process, which was in agreement with previous reports in other species such as dog [11], bull [8], red deer [19], stallion [10] and goats [20]. However, Gravance et al. [21] did not find any overall effect of cryopreservation on goat sperm head morphometry. These contradictory results can be explained by species-specific sensitivity to the freezing process or to different cryopreservation protocols (i.e. glycerol levels, thawing rates, etc.) resulting in a different effect on post-thaw sperm head characteristics $[8,22]$. Moreover, we observed greater heterogeneity (CVs) in thawed samples than in fresh ones, which coincides with Esteso et al. [23] who observed that frozen/thawed red deer semen samples showed higher variability than extended ones for area and length.

We studied the presence of sperm subpopulations in the semen of brown bear, characterized by head morphometry. The cluster analysis rendered three sperm subpopulations with different morphometric features, and we confirmed that the proportions of each subpopulation varied after thawing. Cluster 2 increased its proportion while undergoing a decrease in mean values for sperm head size, whereas Cluster 1 underwent an opposite trend. These variations allow the overall reduction of sperm head dimensions to be described by studying the properties of subpopulations. This method of analyzing small but significant differences among spermatozoa is particularly interesting since the existence of subpopulations of spermatozoa presenting different fertility profiles in the same sample has been reported [9].

Possible explanations for the reduction of morphometric head dimensions after cryopreservation are progressive dehydration of spermatozoa during cryopreservation [24], loss of acrosomal contents [8], loss of sperm membrane functionality [25] and alterations in chromatin condensation [26]. 
It has been suggested that normal sperm morphology may be an indicator of the fertility potential of a given male. Morphological abnormalities in bovine sperm heads have been associated with abnormal chromatin structure [8], and thus it is reasonable to believe that the adverse effects of cryopreservation on head morphology and sperm chromatin may be partly responsible for lowered fertility of spermatozoa observed after cryopreservation. In previous reports, several authors found a good relationship between sperm morphology and sperm chromatin status in human [27], dog [13], bull [28] and koala [29]. We observed good correlations between head morphometric and SCSA parameters of bear sperm: SD-DFI was related with perimeter and area, and DFIt was related to perimeter. We can thus deduce that subtle changes in bear spermatozoa head shape detected by the CASMA system could be related to changes in chromatin structure. It is important to note that both SD-DFI and DFIt have been related to infertility [3].

When we analyzed the classifications of males obtained by the Principal Component Analysis based on SCSA or morphometric parameters, we observed that those males classified as having normal chromatin status $(1,4,6$ and 8$)$ were included only in part in the same quadrant of morphometric classification $(1,3$ and 4). Thus we can infer that both parameter groups did not change in the same way.

In summary, brown bear spermatozoa show a high heterogeneity between animals regarding head morphometry. CASMA demonstrated its utility as a sensitive and objective method of determining morphometric characteristics of bear spermatozoa. The most suitable morphometric parameter for discrimination among individuals seems to be circularity, which might have a practical use for future studies. The cryopreservation process reduced sperm head dimensions and seems to be explained by the presence of several sperm subpopulations with particular characteristics. Finally, we observed good correlation between sperm morphometry and chromatin status detected by SCSA, although qualitative classifications of bears according to the two analysis methods are not completely coincident. In the future, our purpose is to analyze the influence of other factor on sperm quality (for example: age), to evaluate the special features of epidydimal spermatozoa and to optimize the cryopreservation protocols.

\section{Q1 Uncited ${ }_{\Lambda}$ references}

$$
[6,7] \text {. }
$$

\section{Acknowledgements}

This work was supported in part by CANTUR S.A. and CICYT (CGL 2004-02178/BOS). Felipe MartínezPastor was supported by the Juan de la Cierva program (Ministry of Education and Science, Spain).

\section{References}

[1] Holt WV, Bennett PM, Volobouev V. Genetic resource banks in wildlife conservation. J Zool 1996;238:531-544.

[2] Evenson DP, Larson KL, Jost LK. Sperm chromatin structure assay: its clinical use for detecting sperm DNA fragmentation in male infertility and comparisons with other techniques. J Androl 2002;23:25-43.

[3] Evenson DP, Wixon R. Clinical aspects of sperm DNA fragmentation detection and male infertility. Theriogenology 2006;65:979-991.

[4] Garcia-Macias V, Martinez-Pastor F, Alvarez M, Borragan S, Anel L, Paz P. Seasonal changes in sperm chromatin condensation in ram (Ovis aries), red deer (Cervus elaphus) and brown bear (Ursus arctos). J Androl 2006;27(6):837-846.

[5] Ombelet W, Menkveld R, Kruger TF, Steeno O. Sperm morphology assessment: historical review in relation to fertility. Hum Reprod Update 1995;1(6):543-57.

[6] Casey PJ, Gravance CG, Davis RO, Chabot DD, Liu IKM. Morphometric differences in sperm head dimensions of fertile and subfertile stallions. Theriogenology 1997;47:575-82.

[7] Hirai M, Boersma A, Hoeflich A, Wolf E, Foll J, Aumuller R, et al. Objectively measured sperm motility and sperm head morphometry in boars (Sus scrofa): relation to fertility and seminal plasma growth factors. J Androl 2001;22:104-10.

[8] Gravance CG, Vishwanath R, Pitt C, Garner DL, Casey PJ. Effects of cryopreservation on bull sperm head morphometry. J Androl 1998;19:704-9.

[9] Sancho M, Perez-Sanchez F, Tablado L, de Monserrat JJ, Soler C. Computer assisted morphometric analysis of ram sperm heads: evaluation of different fixative techniques. Theriogenology 1998;50:27-37.

[10] Arruda RP, Ball BA, Gravance CG, Garcia AR, Liu IKM. Effects of extender and cryoprotectants on stallion sperm head morphometry. Theriogenology 2002;58:253-6.

[11] Rijsselaere T, Van Soom A, Hoflack G, Maes D, de Kruif A. Automated sperm morphometry and morphology analysis of canine semen by the Hamilton-Thorne analyser. Theriogenology 2004;62:1292-306.

[12] Buendia P, Soler C, Paolicchi F, Gago G, Urquieta B, PerezSanchez F, et al. Morphometric characterization and classification of alpaca sperm heads using the sperm-class analyzer computer-assisted system. Theriogenology 2002;57:1207-18.

[13] Nuñez-Martinez I, Moran JM, Pena FJ. Do computer-assisted, morphometric-derived sperm characteristics reflect DNA status in canine spermatozoa? Reprod Domest Anim 2005;40:537-43.

[14] Gago C, Perez-Sanchez F, Yeung CH, Tablado L, Cooper TG, Soler C. Standardization of sampling and staining methods for the morphometric evaluation of sperm heads in the Cynomolgus monkey (Macaca fascicularis) using computer-assisted image analysis. Int J Androl 1998;21:169-76.

[15] Tablado L, Perez-Sanchez F, Nunez J, Nunez M, Soler C. Effects of exposure to static magnetic fields on the morphology and 
morphometry of mouse epididymal sperm. Bioelectromagnetics 1998;9:377-383.

[16] Thurston LM, Watson PF, Mileham AJ, Holt WV. Morphologically distinct sperm subpopulations defined by Fourier shape descriptors in fresh ejaculates correlate with variation in boar semen quality following cryopreservation. J Androl 2001;22: 382-94.

[17] Gravance CG, Davis RO. Automated sperm morphometry analysis (ASMA) in the rabbit. J Androl 1995;16:88-93.

[18] Thundathil J, Gil J, Januskauskas A, Larsson B, Soderquist L, Mapletoft R, et al. Relationship between the proportion of capacitated spermatozoa present in frozen-thawed bull semen and fertility with artificial insemination. Int J Androl 1999;22:366-73.

[19] Esteso MC, Fernandez-Santos MR, Soler AJ, Garde JJ. Head dimensions of cryopreserved red deer spermatozoa are affected by thawing procedure. Cryo Letters 2003;24:261-8.

[20] Hidalgo M, Rodriguez I, Dorado JM. The effect of cryopreservation on sperm head morphometry in Florida male goat related to sperm freezability. Anim Reprod Sci 2006;100:61-72.

[21] Gravance CG, White C, Robertson KR, Champion ZJ, Casey PJ. The effects of cryopreservation on the morphometric dimensions of caprine sperm heads. Anim Reprod Sci 1997;49:37-43.

[22] Thompson LA, Brook PF, Warren MA, Barratt CL, Cooke ID. A morphometric comparison of the nuclear morphology of fresh and frozen-thawed human zona-bound and unbound sperm. J Androl 1994; 15:337-342.
[23] Esteso MC, Fernandez-Santos MR, Soler AJ, Montoro V, Quintero-Moreno A, Garde JJ. The effects of cryopreservation on the morphometric dimensions of Iberian red deer (Cervus elaphus hispanicus) epididymal sperm heads. Reprod Domest Anim 2006;41:241-246.

[24] England GC. Cryopreservation of dog semen: a review. J Reprod Fertil Suppl 1993;47:243-55.

[25] Marco-Jimenez F, Viudes-de-Castro MP, Balasch S, Moce E, Silvestre MA, Gomez EA, et al. Morphometric changes in goat sperm heads induced by cryopreservation. Cryobiology 2006;52:295-304.

[26] Blottner S, Warnke C, Tuchscherer A, Heinen V, Torner H. Morphological and functional changes of stallion spermatozoa after cryopreservation during breeding and non-breeding season. Anim Reprod Sci 2001;65:75-88.

27] Liu DY, Baker HW. Sperm nuclear chromatin normality: rela- Q2 596 tionship with sperm morphology, sperm-zona pellucida binding, and fertilization rates in vitro. Fertil Steril 1992;58:1178-84.

[28] Ostermeier GC, Sargeant GA, Yandell BS, Evenson DP, Parrish JJ. Relationship of bull fertility to sperm nuclear shape. J Androl 2001;22:595-603.

[29] Johnston SD, López-Fernández C, Gosálbez A, Zee YP, Holt WV, Allen C, et al. The relationship between sperm morphology and chromatin integrity in the koala (Phascolarctos cinereus) as assessed by the Sperm Chromatin Dispersion Test (SCDt). J Androl 2007;28:891-9. 